\title{
At What Extent Physical Training Can Minimize Gender Differences in Male and Female Trained Swimmers? - A Comparative Analysis
}

\author{
Pritha Chatterjee, Priya Nandy, Anupam Bandyopadhyay
}

Department of Physiology, Serampore College William Carey. Road. Serampore, West Bengal. India

\begin{abstract}
This cross sectional study was conducted to analyze the role of effective physical training for minimizing gender differences between trained young male and female swimmers in their body composition and motor fitness level. Height, weight, body fat quantity, flexibility tests for lower back, hamstring, ankle, trunk and neck, elastic leg strength and agility of male and female trained swimmers were measured using standard techniques. Critical swim speed (CSS), 50m swimming and 400m swimming time were taken into consideration to assess their performance level. Mean, standard deviations, $t$-test and correlation co-efficient were calculated for selected variables to justify the results statistically $(p<0.05)$. Insignificant differences were found in body composition between male and female trained young swimmers. Elastic leg strength and agility were significantly $(p<0.05)$ higher in male than female trained swimmer whereas flexibility of lower back and hamstring was significantly $(p<0.05)$ higher in female than male swimmer. Significant positive correlation of CSS ( $p<0.05)$ with height $(m)$, elastic leg strength, flexibility of lower back and hamstring, and ankle in both male and female trained swimmers were found. Effective physical training can minimize body compositional gender differences in trained swimmers. Significant positive correlations of CSS with height, flexibility of lower back, hamstrings and ankle, and elastic leg strength in both male and female trained swimmers suggest musculoskeletal and motor fitness have important role to discriminate male and female swimmers in their performance level and that can definitely be minimize by proper training in female swimmers.
\end{abstract}

Keywords: Critical swim speed, body composition, motor fitness level, trained swimmers.

\section{INTRODUCTION}

Musculoskeletal and motor fitness level influences the overall performance of a swimmer in competition. It can alter the swimming speed of a swimmer during performance. Optimum musculoskeletal and motor fitness enable a swimmer to get maximum speed for his/ her performance ${ }^{[1]}$. It is also found that performance level also varies with gender variation. Male and female swimmers show a variation in their performance level rather in their swimming speed. This may be due to different physiological condition of male and female ${ }^{[2]}$. Swimming causes a specific type of fat distribution in swimmer who is in proper practice. Because of the excessive demands of the exercise on the upper extremities, there is an increase in lean body mass of that region.

Review suggests that the critical velocity is a good estimate of the maximum lactate steady-state for each activity ${ }^{[3]}$. Critical swimming velocity (Vcri) is defined as the swimming velocity which could be theoretically maintained forever without exhaustion. It could serve as an index of endurance swimming performance.

In this study male and female trained swimmers are analyzed in different ways, like body composition, flexibility, leg strength, agility and critical swim speed. Selected variables are statistically correlated with critical swim speed to find out which variables have proper relationship with critical swim speed. The purpose of this study is to focus on gender wise analysis of selected variables and what are the main determinants which influence the critical swim speed in trained young swimmers. Ones we find out the determinants which influence CSS, it is easy to minimize the gender difference by modulating the training. Moreover, critical swim speed is a very good determinant of swimmers' performance level, so the extent to which it is related to musculoskeletal and motor fitness level in both male and female trained swimmers is of prime importance in this study. 


\section{METHODS}

\subsection{Participants}

In this study, male $(n=24)$ and female $(n=12)$ swimmers $(n=24)$, trained for 2 to 9 years with the practice session of 5 days per week and duration of around 2-4 hours per day, were participated. Prior permission of this project was sanctioned by Institutional Human Ethics Committee. Swimmers were taken from a registered swimming club and the criterion was participation at least in district level competition. No one complained about health problem except a few reporting cold \& cough during winter season. Individual National Standard of Living Index and Sports Competition Anxiety Test were performed. All swimming related tests were carried out in a $50 \mathrm{~m}$ pool. A written permission was taken from the club authority to conduct the tests with the consents from the guardians of those swimmers. Ambient temperature and humidity were measured by dry bulb, wet bulb and globe thermometer. All measurements were taken between 7 am to 10 am in consecutive two days. The following measurements were done on each swimmer.

\subsection{Anthropometry and Body Fat Measurement}

\subsubsection{Height $(m)$}

It was measured to the nearest $0.001 \mathrm{~m}$ by an anthropometric rod in standing posture with bare feet in a plane surface.

\subsubsection{Weight $(\mathrm{kg})$}

It was measured to nearest $0.5 \mathrm{~kg}$ by standard weighing pan with bare feet and swimming costumes.

\subsubsection{Body Fat Measurement}

Skin fold Thickness was measured by the help of Harpenden Skin fold Calipers. The total body fat percentage $(\%)$ was calculated using the Siri's Equation ${ }^{[4]}$. The fat mass $(\mathrm{kg})$ was evaluated by using the values of total body fat percentage $(\%)$ and weight $(\mathrm{kg})$. The fat free mass $(\mathrm{kg})$ was calculated deducting the value of fat free mass $(\mathrm{kg})$ from that of the total body mass $(\mathrm{kg})$

\subsection{Flexibility Tests}

\subsubsection{Flexibility test for lower back and hamstring}

The sit and reach test was a common measure of flexibility of lower back and hamstring muscle and was widely used as a general test for flexibility ${ }^{[5]}$.

\subsubsection{Flexibility test for ankle}

This test was done by static ankle flexibility test ${ }^{[6]}$.

\subsubsection{Flexibility test for trunk and neck}

The objective of this test was to monitor the development of the athlete's trunk and neck flexibility ${ }^{[7]}$.

\subsection{Leg Strength Test}

\subsubsection{Elastic leg strength}

For measurement of elastic leg strength, the Vertical Jump Test was done ${ }^{[8]}$.

\subsection{Agility Test}

Agility was measured by shuttle run test ${ }^{[9]}$.

\subsection{Critical swim speed $(\mathrm{m} / \mathrm{sec})$}

The swimmers warmed up for 10 minutes. The first part of the test required the swimmer to swim 400 $\mathrm{m}$. The athlete was instructed to get into the $50 \mathrm{~m}$ swimming pool. After the instructor gave the command GO and started the stopwatch, the swimmer commenced the test. The stopwatch was stopped, the time (T1) was recorded when the swimmer completed the swimming. Then the swimmer had 10 minutes recovery. The second part of the test required the swimmer to swim $50 \mathrm{~m}$. The method of time (T2) measurement was followed like the previous.

$\mathrm{CSS}=(\mathrm{D} 2-\mathrm{D} 1) \div(\mathrm{T} 2-\mathrm{T} 1)$

Where, $\mathrm{D} 1=50 \mathrm{~m}, \mathrm{D} 2=400 \mathrm{~m}, \mathrm{~T} 1=$ time for completion of $50 \mathrm{~m}$ swimming in seconds and $\mathrm{T} 2=$ time for completion of $400 \mathrm{~m}$ swimming in seconds ${ }^{[10]}$. 


\subsection{Statistical Analysis}

Mean values and standard deviations of each mentioned parameters of both sexes were calculated by using Microsoft Excel 2010.The Unpaired two tails T test was also undertaken in Microsoft Excel 2010 to predict any possible gender differences regarding these parameters. The correlation ( $r$ ) values of CSS $(\mathrm{m} / \mathrm{sec})$ with selected variables were evaluated. The level of significance was taken at $\mathrm{p}<0.05$.

\section{RESUlts}

The mean values, standard deviation and level of significance of age (yrs), height $(\mathrm{m})$, weight $(\mathrm{kg})$, total body fat percentage $(\%)$, total fat mass $(\mathrm{kg})$, fat free mass $(\mathrm{kg})$, flexibility of lower back \& hamstring (m), ankle (m), trunk and neck flexibility (m), elastic leg strength (sec), agility (sec), swim time of $400 \mathrm{~m}$, swim Time of $50 \mathrm{~m}$ and Critical Swim Speed in male $(\mathrm{n}=24)$ and female $(\mathrm{n}=12)$ trained swimmers are shown in Table 1. Statistical insignificant differences are observed in male and female trained swimmers in age, height, weight, total body fat percentage $(\%)$, total fat mass and fat free mass (Table 1).The flexibility of lower back and hamstrings are significantly higher $(\mathrm{p}<0.05)$ in female than male (Table 1). Insignificant differences are found in ankle, neck and trunk flexibility between male and female swimmers (Table 1).Elastic leg strength is found higher in male swimmer than female swimmer and it is statistically $(\mathrm{p}<0.05)$ significant (Table 1$)$. Male swimmers are more agile than female swimmers though the difference is statistically insignificant (Table 1).

In Table 2, the correlation values and level of significance of critical swim speed with height $(\mathrm{m})$, weight $(\mathrm{kg})$, total body fat percentage $(\%)$, total fat mass $(\mathrm{kg})$, fat free mass $(\mathrm{kg})$, flexibility $(\mathrm{m})$, elastic leg strength $(\mathrm{sec})$ and agility $(\mathrm{sec})$ of both male and female trained swimmers are represented. There is positive correlation between CSS and height $(\mathrm{m})$ in both male and female trained swimmers and it is statistically $(\mathrm{p}<0.05)$ significant (Table 2$)$. Statistically insignificant correlations are found between CSS and weight $(\mathrm{kg})$ in both male and female trained swimmers (Table 2).Negative insignificant correlations are found between CSS and total body fat percentage in both male and female trained swimmers (Table 2$)$. There is statistically positive correlation $(\mathrm{p}<0.05)$ between CSS and fat free mass $(\mathrm{kg})$ in male trained swimmers but female trained swimmers show insignificant positive correlations (Table 2). The CSS with flexibility of lower back and hamstrings, neck, and ankle have shown positive significant $(\mathrm{p}<0.05)$ correlations in both male and female trained swimmers (Table 2).But insignificant positive correlations of trunk and neck flexibility with CSS in both male and female trained swimmers are found in this study (Table 2).Elastic leg strength shows statistically significant $(\mathrm{p}<0.05)$ correlations with CSS in both male and female trained swimmers (Table 2).

Table1.The mean values, standard deviation and level of significance of age (yrs), height ( $m$ ), weight (kg), total body fat percentage (\%), fat free mass (kg), flexibilities of lower back, ankle, trunk and neck, elastic leg strength, agility, performance time (sec) of $400 \mathrm{~m}$ and $50 \mathrm{~m}$, and critical swim speed $(\mathrm{m} / \mathrm{sec}$ ) of trained young male and female swimmers

\begin{tabular}{|l|c|c|c|}
\hline \multicolumn{1}{|c|}{ VARIABLES } & $\begin{array}{c}\text { MALE }(\mathbf{n = 2 4}) \\
\text { Mean } \pm \text { SD }\end{array}$ & $\begin{array}{c}\text { FEMALE }(\mathbf{n}=12) \\
\text { Mean } \pm \text { SD }\end{array}$ & $\begin{array}{c}\text { Level of } \\
\text { significance }\end{array}$ \\
\hline Age (years) & $14.13 \pm 1.42$ & $14.25 \pm 1.79$ & NS \\
\hline Height $(\mathrm{m})$ & $1.58 \pm 0.11$ & $1.57 \pm 0.06$ & NS \\
\hline Weight $(\mathrm{kg})$ & $49.08 \pm 11.73$ & $45.96 \pm 7.86$ & $\mathrm{NS}$ \\
\hline Total Body Fat \% & $9.08 \pm 3.61$ & $8.35 \pm 2.46$ & $\mathrm{NS}$ \\
\hline Total Fat Mass $(\mathrm{kg})$ & $4.86 \pm 2.42$ & $3.97 \pm 1.71$ & $\mathrm{NS}$ \\
\hline Fat Free Mass $(\mathrm{kg})$ & $45.84 \pm 11.51$ & $41.99 \pm 6.47$ & $\mathrm{NS}$ \\
\hline Flexibilities of Lower back and Hamstrings (m) & $0.28 \pm 0.01$ & $0.44 \pm 0.12$ & $\mathrm{P}<0.05$ \\
\hline Flexibility of Ankle (m) & $0.46 \pm 0.1$ & $0.46 \pm 0.07$ & $\mathrm{NS}$ \\
\hline Flexibilities of Trunk and Neck (m) & $0.45 \pm 0.10$ & $0.44 \pm 0.11$ & $\mathrm{NS}$ \\
\hline Elastic Leg Strength (m) & $0.13 \pm 0.02$ & $0.11 \pm 0.02$ & $\mathrm{P}<0.05$ \\
\hline Agility (sec) & $11.86 \pm 0.75$ & $12.06 \pm 0.70$ & $\mathrm{NS}$ \\
\hline Performance Time (sec) of 400m Free Style & $356.44 \pm$ & $393.31 \pm 45.30$ & $\mathrm{P}<0.05$ \\
Swimming & 36.18 & & \\
\hline $\begin{array}{l}\text { Performance Time (sec) of 50m Free Style } \\
\text { Swimming }\end{array}$ & $35.13 \pm 4.08$ & $38.36 \pm 4.73$ & $\mathrm{P}<0.05$ \\
\hline Critical Swim Speed (m/sec) & $1.10 \pm 0.11$ & $1.0 \pm 0.11$ & $\mathrm{P}<0.05$ \\
\hline
\end{tabular}

NS = Not Significant, $p=$ Level of Significance. 
Table2. Correlation coefficient ( $r$ ) values and level of significance between critical swim speed and some selected variables like height, weight, total body fat, fat free mass, flexibilities of lower back and hamstrings, ankle, trunk and neck and elastic leg strength of trained young male and female swimmers.

\begin{tabular}{|l|c|c|}
\hline \multicolumn{1}{|c|}{ VARIABLES } & $\begin{array}{l}\text { MALE }(\mathbf{n = 2 4}) \text { r values and } \\
\text { level of significance }\end{array}$ & $\begin{array}{l}\text { FEMALE (n=12) r } \\
\text { values and level of } \\
\text { significance }\end{array}$ \\
\hline CSS $(\mathrm{m} / \mathrm{sec})$ and Height $(\mathrm{m})$ & $0.548^{*}$ & $0.580^{*}$ \\
\hline CSS $(\mathrm{m} / \mathrm{sec})$ and Weight $(\mathrm{kg})$ & $0.342^{\mathrm{ns}}$ & $0.124^{\mathrm{ns}}$ \\
\hline CSS $(\mathrm{m} / \mathrm{sec})$ and Total Body Fat \% & $-0.120^{\mathrm{ns}}$ & $-0.282^{\mathrm{ns}}$ \\
\hline CSS $(\mathrm{m} / \mathrm{sec})$ and Fat Free Mass $(\mathrm{kg})$ & $0.507^{*}$ & $0.187^{*}$ \\
\hline $\begin{array}{l}\text { CSS }(\mathrm{m} / \mathrm{sec}) \text { and Flexibility of Lower back \& } \\
\text { Hamstrings }(\mathrm{m})\end{array}$ & $0.679^{*}$ & $0.603^{*}$ \\
\hline CSS $(\mathrm{m} / \mathrm{sec})$ and Flexibility of Ankle $(\mathrm{m})$ & $0.623^{*}$ & $0.458^{*}$ \\
\hline $\begin{array}{l}\text { CSS }(\mathrm{m} / \mathrm{sec}) \text { and Flexibilities of Trunk \& Neck } \\
(\mathrm{m})\end{array}$ & $0.043^{\mathrm{ns}}$ & $0.244^{\mathrm{ns}}$ \\
\hline CSS $(\mathrm{m} / \mathrm{sec}$ and Elastic Leg Strength $(\mathrm{m})$ & $0.400^{*}$ & $0.348^{*}$ \\
\hline
\end{tabular}

$*=p<0.05$ and ${ }^{n s}=$ not significant

\section{DisCUSSIONS}

Swimmers are usually tall and relatively lean. Some body fat is not a hindrance as it can add to buoyancy in water ${ }^{[11]}$ (Wilmore, J.H. and Costill, D.L., 1994). Weight is not only gained by the muscle but also by the fat accumulation. The moderate fat level can help in floating and reduces the energy demand for floating. This can be used as the fuel source of swimming stroke. Males have a more central distribution of fats than females who displayed a build-up of fats in legs. In this study, trained male and female swimmers are in same age group and almost have similar body composition (height, weight, total body fat percentage, total fat mass and fat free mass). Insignificant differences in body composition (Table 1) between young trained male and female swimmers are definitely achieved by effective training sessions. This study reveals that effective training can minimize body compositional gender difference in young trained swimmers.

Significant difference in elastic leg strength of male and female trained swimmers indicates leg strength is a major determinant in performance level (Table 1). CSS is significantly higher in male $(1.10 \mathrm{~m} / \mathrm{sec})$ than female $(1.0 \mathrm{~m} / \mathrm{sec})$ swimmer and eventually performance times of $400 \mathrm{~m}$ and $50 \mathrm{~m}$ free style swim are significantly higher in male swimmer (Table 1).Lower CSS in female swimmers lead to less performance time in both $400 \mathrm{~m}$ and $50 \mathrm{~m}$ free style than male swimmers and it is obviously due to less elastic strength and agility in trained female swimmers. Effective training minimizes body compositional variation but difference in motor fitness exists between the two groups. Lower back and hamstrings are significantly more flexible in female than male swimmers may be due to more centrally deposited fat in male though this study cannot claim, as it is not estimated. Insignificant flexibilities of ankle, trunk and neck in male and female swimmers suggest that effective training can minimize the gender differences in young swimmers.

The positive correlations among CSS and height, elastic leg strength, flexibilities of lower back and hamstrings, and ankle (Table 2) have suggest critical swim speed can modified by these variables in both sexes. Moreover, significant correlation between CSS and fat free mass in male swimmers is another criterion to dominate over female swimmers in their performance time. This study reveals that in both sexes, CSS decrease when total body fat increases though it is statistically insignificant (Table 2).

\section{Practical Applications}

Genetically regulated morphometric gender differences can minimize by improving proper variables in female swimmers. Performance level of both sexes is enhanced by modulating certain phenotypical features in young trained swimmers. So to get better performance in swim time specific emphasis should be taken by the coaches apart from their regular exhaustive swimming.

\section{Conclusions}

Effective physical training can minimize certain body compositional differences between trained young male and female swimmers. Performance level in swimmers is highly associated with their height, fat free mass, elastic leg strength, flexibilities of certain parts of body and agility. Improving 
these variables by proper training, female swimmers are able to perform the same as male swimmers. This study also reflects that by considering proper importance of the above mentioned variables, critical swim speed as well as performance time can be improve in both male and female swimmers.

\section{ACKNOWLEDGMENTS}

We acknowledge our sincere thanks to the Institutional Human Ethics Committee to give us permission to perform this research works. We are also thankful to club authorities, coaches and each participant swimmers.

\section{REFERENCES}

[1] Beashel P, Taylor J. Advanced Studies in Physical Education and Sport, UK: Thomas Nelson \& Sons Ltd, 1996.

[2] Buśko K, Michalski R, Mazur J, Gajewski J. Jumping abilities in elite female volleyball players: comparative analysis among age categories. Biol. Sport, 2012; 29:p.317-319.

[3] Fernandes R, Aleixo I, Soares S, Vilas-Boas JP. Anaerobic Critical Velocity: a new tool for young swimmers training advice. New York: Nova Science Publishers, 2008; p. 211-223.

[4] Siri WE. Techniques for measuring body composition. Washington DC: National Academy of Sciences, 1961; p. 223-244.

[5] Chillon P, Castro-Piñero J, Ruiz Jr, Soto Vm, Carbonell-Baeza A, Dafos J, Vicente-Rodriguez G, Castillo Mj, Ortega Fb. Hip Flexibility Is The Main Determinant Of The Back-Saver Sit-AndReach Test In Adolescents. Journal of Sports Sciences, 2010; 28(6):p.641-648. [Pubmed].

[6] Beashel P, Taylor J. The World of Sport Examined, Croatia, Thomas Nelson and Sons, 1997; 57.

[7] MacKenzie SC, Tuteja R. Modular Capabilities for the Canadian Navy's Single Class Surface Combatant: A Perspective on Flexibility, Defense R\&D Canada Contract Report, 2006.

[8] Sargent DA. The Physical Test of a Ma. American Physical Education Review. 1921; 26:p.188194.

[9] Tomchuk D. In Companion guide to measurement and evaluation for kinesiology, Sudbury, MA: Jones \& Bartlett Learning, 2011.

[10] Wakayoshi K, Yoshida T, Udo M, Harada T, Moritani T, Mutoh Y, Miyashita M. Does critical swimming velocity represent exercise intensity at maximal lactate steady state?, Eur. J. Appl. Physiol, 1993; 66: p.90-95.

[11] Wilmore JH, Costill DL. Physiology of sport and exercise, Champaign, IL: Human Kinetics, 1994. 